\title{
LA MOTIVACIÓN DE LA SENTENCIA EN EL PROCEDIMIENTO MONITORIO LABORAL: ¿UNA CONCESIÓN GRACIOSA DEL ÓRGANO JURISDICCIONAL?
}

\author{
THE MOTIVATION OF THE JUDGMENT IN THE ORDER FOR \\ PAYMENT PROCEDURE FOR LABOR MATTERS: A GRACIOUS \\ CONCESSION OF THE JURISDICTIONAL ORGAN?
}

\author{
Jordi Delgado Castro* \\ Diego Palomo Vélez ${ }^{*}$ \\ René ACEVEdo SAZO ${ }^{* * *}$
}

\begin{abstract}
RESUMEN: El procedimiento monitorio laboral se ha consolidado como uno de los instrumentos más importantes para impartir justicia en el orden laboral. Sin embargo, existen desajustes prácticos que ameritan una correcta reflexión teórica con el objetivo de proponer mejoras y criterios de interpretación acordes a la técnica monitoria. En concreto este artículo realiza un análisis y propuesta de superación a la actuación del juez en el momento de dictación de la sentencia.
\end{abstract}

Palabras clave: Procedimiento monitorio laboral, Problemas monitorio, Rol del juez laboral.

ABSTRACT: The Order for payment procedure has established itself as one of the most important tools for justice in labor litigation. However, there are practical imbalance that call for a correct theoretical meditation with the objective of proposing improvements and interpretation criteria according to the best for order for payment procedure technique. In addition, this paper makes and analysis and a proposal to the role of the judge in this type of proceedings.

Key words: Labor For payment Procedure, For Payment procedure issues, Role of the workers court judge.

\footnotetext{
* Profesor de Derecho Procesal, Universidad Austral de Chile. Doctor en Derecho, Universidad de Barcelona (España). Dirección postal: Campus Isla Teja s/n, Valdivia. Dirección electrónica: jordi.delgado@uach.cl. Este trabajo corresponde a parte de los resultados del Proyecto financiado por el Proyecto de Investigación Fonecyt Regular No 1160832, titulado: "Estudio crítico del procedimiento monitorio laboral chileno: O sobre como un deficiente diseño legislativo puede abrir la puerta a más problemas que soluciones" del que los autores son investigadores y al que se hace presente el agradecimiento por la financiación de este estudio.

** Profesor de Derecho Procesal, Universidad de Talca. Doctor en Derecho, Universidad Complutense de Madrid (España). Dirección postal: 1 Poniente, 1141, Talca. Dirección electrónica: dpalomo@utalca.cl

*** Abogado, Magíster en Derecho mención Derecho Procesal, Universidad de Talca. Dirección postal: 1 Sur, 690, Talca. Dirección electrónica: reneacevedo@legista.cl
} 


\section{INTRODUCCIÓN}

El procedimiento monitorio laboral, fue introducido en nuestro ordenamiento jurídico mediante la Ley No $20.087^{1}$. Busca entregar una herramienta que tutele, con suma urgencia ${ }^{2}$, a aquellos trabajadores que detenten créditos de menor entidad, esto es, aquellos cuya cuantía sea igual o inferior a diez ingresos mínimos mensuales, así como a los trabajadores amparados por el fuero que les concede el artículo 201 del Código del Trabajo. Su incorporación, como procedimiento especial, es una de las marcas más claras de un nuevo sistema procesal laboral, que recogiendo la vasta experiencia del Derecho comparado ${ }^{3}$, tiende a la simplificación de las fórmulas procesales en búsqueda de la siempre deseada celeri$\mathrm{dad}^{4}$. El trabajador que opte por la vía monitoria, debiera tener un camino más expedito ${ }^{5}$ hacia la sentencia definitiva ${ }^{6}$, en comparación con aquel que utilice el procedimiento de aplicación general. Más importante aún, tendrá un tratamiento probatorio que morigerará su obligación de demostrar sus alegaciones a un punto tal que, si estuviéramos en una provincia distinta de nuestro ordenamiento jurídico, representaría una vulneración inaceptable a las garantías del debido proceso ${ }^{7}$. Sin embargo, por tratarse de créditos de escaso monto y

1 La historia de cómo llega a nuestro ordenamiento jurídico está excelentemente tratada en PerEIRA (2010). En él se muestra el camino legislativo, las reformas y sus principales modificaciones

2 Así, desde sus orígenes el procedimiento monitorio nace con este espíritu, véase Calamandrei (2006) p. 21.

3 Navarro (2011) p. 19.

4 Principio recogido específicamente, con una discutible técnica legislativa, como uno de los que ha de gobernar el procedimiento en el ámbito laboral. Y, sin duda, un deseo siempre presente en la Justicia, como lo apuntaba con maestría COUTURE (1951). En lo específico, el procedimiento monitorio contribuye a materializar este principio, en tanto, que incluso en los supuestos procesalmente más complejos, los tiempos de resolución no suelen extenderse más allá de un mes. Por su parte, los casos más sencillos en que el demandado no se opone pueden conducir a la creación de un título ejecutivo en un tiempo menor a 10 días desde la presentación de la demanda. Sin embargo, hay que ser conscientes que no todo lo rápido es necesariamente bueno y existen atropellos procesales derivados de una visión excesivamente resultista que funda sus postulados unidimiensionalmente en las estadísticas; ello es descrito especialmente por Palomo (2015) pp. 384-389.

5 El procedimiento monitorio se caracteriza por tratar de obtener: "el máximo resultado en la aplicación de la ley, pero con el menor desgaste del proceso judicial”. Orellana (2008) p. 80.

6 La ansiada sentencia definitiva puede obtenerse en dos instantes aunque en rigor solamente podamos hablar de uno, que motiva esta investigación. En efecto, si ante la demanda monitoria, el tribunal acoge y el deudor no se opone esta resolución hará las veces de sentencia definitiva. Orellana (2015) p. 152. Sin embargo, la sentencia definitiva, propiamente tal, se dictará tras una audiencia única de juicio. Esta resolución, en atención a los plazos que el legislador ha diseñado, debiera obtenerse en un tiempo más breve que en el juicio ordinario LANATA (2011) p. 119-121.

7 Efectivamente, una de las ventajas que permite el procedimiento monitorio es que se acojan las peticiones en base a los dichos del demandante, sin siquiera haberse propuesto, admitido y rendido formalmente una etapa probatoria. En algunos modelos, empero, se solicita que se acompañe un principio de prueba y hablamos de procedimientos monitorios de tipo documental (una explicación más desarrollada sobre el particular en Delgado (2015) pp. 13-19). Ello, no obstante, no significa una vulneración a los postulados elementales del debido proceso, en tanto, la técnica de la inversión del contradictorio viene siendo aceptada por los operadores jurídicos, sin mayores cuestionamientos que merezcan atención. Pérez Ragone (2006) p. 209: "El derecho de defensa se garantiza brindándole oportunidad para ser oído y oponerse”. 
contiendas relativas al fuero maternal, nuestro legislador optó por hacer primar la urgencia procesal y entregar un procedimiento realmente ágil a los trabajadores ${ }^{8}$.

Una de las características más destacables de nuestro procedimiento monitorio laboral es la regulación de la sentencia definitiva ${ }^{9}$. En la misma línea de lo descrito, lo cierto es que llama, a priori, poderosamente la atención la forma en cómo se soslayan los elementos centrales que, entendemos toda sentencia debe contener ${ }^{10}$. Las menciones centrales de la resolución, más importante, en materia laboral -y en general, en la resolución de todo conflicto jurídico- se encuentran consagrados, en su vertiente más tradicional, en el artículo 459 del Código del Trabajo. Sin embargo, existe una norma específica atingente al procedimiento monitorio; el artículo 501, apoyándose en una remisión al citado 459, excluye expresamente dos requisitos fundamentales: la síntesis de los hechos y de las alegaciones de las partes y, lo que parece más sorprendente, el análisis de la prueba rendida, los hechos que se estimen probados y el razonamiento que conduce a esta estimación. Por lo tanto, según lo descrito, el juez no está obligado, en un sentido estricto, a motivar sus sentencias. Esta es la interpretación que ha acogido buena parte de la jurisprudencia ${ }^{11}$.

La regla descrita genera, al menos, dos graves vulneraciones a las garantías procesales mínimas de todo justiciable: En primer lugar, se lesiona el derecho de defensa ${ }^{12}$. Adicionalmente, sumado a la perplejidad de quien es destinatario de una sentencia definitiva sin

${ }^{8}$ Es evidente que, cuando un trabajador no recibe su salario queda en una posición negocial nefasta que le obliga a llegar a acuerdos injustos para sus propios intereses. En la Historia de la Ley No 20.087 se puede observar cómo el legislador celebraba este tipo de medidas en tanto, por ejemplo la Diputada señora Adriana Muñoz clamaba por la celeridad y la tutela judicial efectiva de los trabajadores al indicar: "Un trabajador o trabajadora al que no se le paga su salario no puede pagar el dividendo, no puede pagar la colegiatura de sus hijos ni tampoco puede alimentarse. Eso es pobreza, eso es desigualdad. Esto es lo que está sucediendo en el Chile de hoy, donde los juicios laborales demoran hasta cinco o seis años. Si un trabajador gana un juicio laboral, el empleador en lugar de pagar los 500 mil pesos que le adeuda, prefiere apelar a la corte de apelaciones y recurrir a la Corte Suprema”. Sin embargo, debemos tener bien presente que más que para restablecer escenarios de desigualdad de partes, el procedimiento monitorio surge con el objeto de tutelar créditos aparentemente incontrovertidos. Delgado (2015) p. 29; esa misma lógica se puede aplicar perfectamente al procedimiento monitorio laboral.

9 Lo destacaba acertadamente Orellana (2010) pp. 66 y 67. Fue, probablemente, el primer autor que detectó esta curiosa forma de plantear el fallo en el procedimiento monitorio y descartó, inmediatamente, que aquello fuera un proceder posible y acorde a nuestra legislación procesal laboral, ni constitucional.

10 Obligación de motivar la sentencia que arraiga su obligatoriedad y difusión entre los ordenamientos procesales de civil law de la Europa contiental durante la segunda mitad del siglo XVIII. TARUFFo (1975) p. 319-323.

11 En este sentido, baste citar algunos ejemplos: SAAVEDRA CON HIPERMERCADO LA SERENA LIMITADA (2010); BArrientos con Dálila (2010); Contreras con MakluF (2015); Gonzalez Rodríguez con Pomerape S.A (2016); URRUTIA CON LEIVA (2016); OYARZO CON READY MIX CENTRO S.A. (2017); HERNANDEZ CON ILUSTRE MUNICIPALIDAD DE PANGUIPULLI (2017); Sin embargo, también podemos encontrar algún fallo que propone lo contrario, RANDSTAD CON INSPECCIÓN DEL TRABAJO DE COYHAIQUE (2017): "todo juicio requiere de una razón suficiente el que debe estar suficientemente fundado y construido sobre la base de deducciones razonables, lógicas y originadas de las pruebas existentes, obligación de la que el Juez no se encuentra liberado aun cuando se trate de un procedimiento monitorio, puesto que la motivación de la sentencia obliga a este a correlacionar lógicamente los argumentos y probanzas allegadas con el objeto de evitar una arbitrariedad".

12 Nieva (2014) p. 156: "La razonabilidad es fundamental en la motivación. Exige del tribunal que exponga los motivos por los que se inclina a favor de acoger o no una petición”. Continúa el mismo, p. 158: "el derecho vulnerado es el de defensa, dado que al no tener acceso a los motivos del juez, el litigante no se puede defender de la sentencia en los recursos porque no tiene razones que rebatir". 
el contenido más importante, acarrea como consecuencia una disminución mayor a las posibilidades de ejercer el derecho al recurso de los justiciables, máxime, si recordamos que dicha garantía ya se encuentra limitada por la naturaleza propia del recurso de nulidad ${ }^{13}$, única vía de impugnación de la sentencia definitiva en materia laboral.

Lo anterior es del todo lógico si consideramos que una de las causales de nulidad más usada por los recurrentes es la contenida en el artículo 478 letra b) que se refiere a la infracción manifiesta de las normas sobre la apreciación de la prueba conforme a las reglas de la sana crítica. En definitiva, no solo se vería afectado el derecho de los justiciables a obtener una sentencia suficientemente motivada, sino que también se vería seriamente degradado su derecho al recurso, en tanto, la parte que se vea agraviada ${ }^{14}$ por una resolución no sabría el razonamiento que llevó al juez a tomar esa decisión y se le impediría, en los hechos, la posibilidad de ejercer un recurso con esperanzas razonables de acogimiento. Se constata, de este modo, un escenario bastante arduo para el recurrente si se atiende, a mayor abundamiento, al porcentaje elevadísimo de recursos de nulidad rechazados ${ }^{15}$. Pero con independencia de la impetración de un recurso, el justiciable no podrá conocer las razones o motivos que condujeron al juez a fallar en un sentido u otro.

Es, en este contexto, que observamos como principal objetivo de este trabajo proponer una interpretación, eminentemente dogmática, del artículo 501 del Código del Trabajo acorde a los estándares mínimos que exige la solución de todo proceso. Una exégesis que en ningún caso libera al sentenciador de la obligación de motivar sus sentencias en el procedimiento monitorio; por añadidura, observaremos cómo se ha acogido esta regla en la práctica forense tomando una muestra aleatoria que nos permita reforzar nuestras conclusiones.

Nuestra principal hipótesis es que el legislador, en ningún caso, quiso rebajar las exigencias de la solución al conflicto, al punto de entregar al justiciable una sentencia sin los elementos más significativos para poder entenderla como tal y, por lo tanto, la lectura del procedimiento laboral debe ser realizada en su contexto global, para encontrar una respuesta adecuada jurídica y técnicamente (procesalmente).

Partiendo de la base que nuestra premisa es que el justiciable tiene derecho a una sentencia debidamente fundada, trataremos de encontrar argumentos que apunten en aquella dirección, para luego contrastarlo con lo que nuestros tribunales de justicia, efectivamente, han entendido.

\section{ESTADO DEL ARTE A PROPÓSITO DEL INCISO TERCERO DEL ARTÍCULO 501 DEL CÓDIGO DEL TRABAJO}

Pareciera que "el pretor no se ocupa de cosas nimias" y, la doctrina no ha sido suficientemente estudiosa de este tema. Se acepta, sin excesivos cuestionamientos ${ }^{16}$ el tenor

\footnotetext{
13 Es especialmente acucioso el estudio de Palomo y LorCa (2017) pp. 37-71.

14 Elemento esencial de nuestro sistema de recursos de la misma forma que lo describe MonTERo (2014) p. 436.

15 Un estudio empírico en Humeres (2010) p. 187-197.

16 Al respecto, por dar un ejemplo que se repite recurrentemente, la ICA Santiago ha sostenido: "es precisamente de aquellos requisitos que expresamente el legislador ha permitido omitir en el pronunciamiento de sentencias definitivas que se dicten en el marco de un procedimiento monitorio, según preceptúa claramente el
} 
literal del inciso tercero del artículo 501 como una facultad entregada por el legislador al juez para omitir en su sentencia definitiva la síntesis de los hechos y de las alegaciones de las partes y el análisis de toda la prueba rendida, los hechos que estime probados y el razonamiento que lo conduce a esta estimación ${ }^{17}$. Sin embargo, pero sin llegar a plantear una nueva interpretación de la norma que obligue al juez a desarrollar en sus resoluciones todos los elementos contenidos en el artículo 459 CT, se han realizado ciertas precisiones que buscan resguardar la constitucionalidad de la sentencia monitoria o, al menos, su armonía con las garantías del debido proceso. En esta línea, parte de la doctrina matiza que del mismo tenor literal del artículo 501 inciso tercero se desprende que se releva al juez del análisis de toda la prueba rendida, pero no sucede lo mismo respecto de aquella que lo llevó a la conclusión a la que llegó y, por otro lado, no se le ha eximido de manera alguna de fallar en conformidad a las reglas de la sana crítica ${ }^{18}$, con todo lo que ello significa, ergo, no puede fallar en conciencia ${ }^{19}$.

Una alternativa distinta y que busca consagrar en el procedimiento monitorio la obligación de fundamentar las sentencias, señala -con idéntica inspiración a la que nosotros proponemos-, que la ausencia de la motivación no puede justificarse por la carencia aun de descripción legislativa, ya que tal ausencia se suple por la consagración constitucional de la motivación como elemento subyacente al debido proceso $^{20}$; de modo que, resulta inadmisible el subterfugio utilizado por los magistrados a cargo de conocer el recurso de nulidad, el no acogerlo o declararlo inadmisible por tratarse de un procedimiento monitorio que omite la ponderación de la prueba en la sentencia. Tal respuesta, en la misma línea, es un ejemplo más del formalismo lógico judicial excesivo, como expresión de la deformación rituaria en el proceso $^{21}$; de paso, una demostración de la dinámica en la cual se desenvuelve, en la práctica el referido recurso de nulidad.

citado artículo 501 del Código del Trabajo, por lo que éste arbitrio deberá ser rechazado". SERVICIOS LIMITADA CON INSPECCIÓN PROVINCIAL DEL TRABAJO DE SANTIAGO (2017).

17 Palavecino y Ramírez (2010) p. 75.

18 El sistema de valoración probatorio en los procesos reformados y, específicamente, en el procedimiento laboral es el de la sana crítica. Ello es una afirmación que no resulta baladí, puesto que asumir esta premisa, significa tener claro que esta definición acarrea como consecuencia que entendamos que: "el sistema de sana crítica está intrínsecamente relacionado con la motivación de la sentencia, de forma que podría llegarse al extremo de afirmar que no podría darse tal sistema de valoración sin la fundamentación de la sentencia. Y es que sin motivación de la sentencia no existe seguridad alguna de que se hayan utilizado criterios racionales en la valoración" (Maturana (2014) p. 115).

19 Lanata (2011) p. 186. Utilizando esta expresión con la que Couture (1951) p. 176, describió a este sistema probatorio libre: "Tu fallas como tu conciencia te lo diga, con la prueba de autos, sin la prueba de autos y aun contra la prueba de autos". Sistema lejos del sistema probatorio chileno y que tiene diferencias con el sistema de prueba libre llamado íntima convicción, si bien comparte males como la ausencia de motivación, la mera declaración (y no actividad de valoración) de voluntad que conduce, inevitablemente, a la arbitrariedad (MONTERO (2011) pp. 600-601).

20 Por ejemplo, Orellana (2010) pp. 66 y 67 después de explicar cómo funcionan las previsiones recogidas en el Código del Trabajo concluye categóricamente: "no puede haber un proceso racional y justo sin una sentencia motivada".

${ }^{21}$ Domínguez (2010) p. 159. 
En el caso de la jurisprudencia, como ya adelantáramos, nuestra jurisdicción mayor ha interpretado el inciso tercero del artículo 501 como una morigeración absoluta de la obligación del juez de motivar sus sentencias en el procedimiento monitorio: los jueces del trabajo no estarían obligados a incluir en sus sentencias definitivas los elementos contenidos en los números 3 y 4 del artículo 459 del Código del Trabajo. En este sentido, la Corte de Apelaciones de Valparaíso señala: "En efecto, tratándose en la especie de un procedimiento monitorio, cobra aplicación la norma del inciso tercero del artículo 501 del Código del Trabajo, que prescribe que el juez deberá dictar sentencia al término de la audiencia, la que deberá contener las menciones señaladas en los números 1, 2, 5, 6 y 7 del artículo 459, es decir, la sentencia monitoria no requiere una síntesis de los hechos y de las alegaciones de las partes; tampoco el análisis de toda la prueba rendida, ni los hechos que estime probados, ni el razonamiento que conduzca a dicha estimación. [...] En consonancia con lo anterior, no parece que el recurso de nulidad sea procedente por todas las causales en el caso del procedimiento monitorio. En efecto, si la sentencia no requiere contener el análisis de toda la prueba rendida, los hechos que estima probados y el razonamiento que conduce a dicha estimación, imposible resulta entrar a revisar si aquella ha si pronunciada con infracción manifiesta de las normas sobre apreciación de la prueba conforme a las reglas de la sana crítica" 22 .

La misma postura la vemos, por ejemplo, en algunos fallos de la Corte de Apelaciones de Arica, como aquel que resuelve: "Que cabe dejar sentado que en cuanto a la apreciación de la prueba, y tal como ha sostenido la propia recurrente, el artículo 501 del Código del Trabajo -norma especial del procedimiento monitorio que prima sobre una regla general- ordena que la sentencia recaída en el procedimiento contenga las menciones de los número 1, 2, 5, 6 y 7 del artículo 459 del mismo código, liberando al tribunal laboral precisamente de la carga de incorporar a su fallo el análisis de toda la prueba rendida, los hechos que estime probados y el razonamiento que conduce a esa estimación ( No 4 del artículo 459) comportamientos que el recurrente exige. Imposible, se hace entonces, el cumplimiento simultáneo del artículo 459, pues la incompatibilidad entre ambas normas es absoluta, debiendo ceder dicha disposición del 459 -en atención al principio de especialidaden favor de lo previsto en el artículo 501 inciso final, ambos del Código del Trabajo"23.

Finalmente, en la misma línea y a modo de ejemplo, la Ilustrísima Corte de Apelaciones de Valdivia señala: "cabe colacionar que la procedencia del recurso de nulidad por el motivo de anulación del artículo 478 letra b) del Código del Trabajo para impugnar la sentencia definitiva dictada en el procedimiento monitorio, ha de interpretarse en relación a lo previsto en los artículos 501 y 459 del mismo cuerpo legal, toda vez que, en este procedimiento especial, el Juez no tiene la obligación legal de analizar toda la prueba rendida, fijar los hechos que estime probados ni el razonamiento que conduce a esa estimación" 24 .

Por lo tanto, con matices menores, la jurisprudencia de las Cortes de Apelaciones considera que el artículo 501 del Código del Trabajo libera al juez de su obligación de mo-

\footnotetext{
CONTRERAS CON MAKLUF (2015).

3 Gonzalez Rodríguez con Pomerape S.A (2016)

${ }^{24}$ Hernández CON ILUSTRE Municipalidad de PANGUipulli (2017).
} 
tivar sus sentencias en un procedimiento monitorio ${ }^{25}$, lo que, en consecuencia, limita las causales posibles para una eventual nulidad. Todo lo anterior por el tenor literal del inciso tercero del artículo 501 y el principio de especialidad que lo haría primar por sobre el artículo 459.

También, en el plano jurisprudencial, corresponde recordar el pronunciamiento que hiciera nuestro Tribunal Constitucional respecto a la constitucionalidad del inciso tercero del artículo 501, hecho en virtud del requerimiento que hiciera la Ilustrísima Corte de Apelaciones de Talca. Con fecha 12 de octubre del año 2010, la corte Constitucional resolvió rechazar la observación de inconstitucionalidad del precepto legal, teniendo como fundamento principal que la exclusión del recurso de nulidad por infracción manifiesta a las normas sobre apreciación de la prueba, como consecuencia del precepto cuestionado, no priva a los interesados absolutamente de dicho medio de impugnación, ya que deja subsistente la causal genérica del artículo 477 del Código del Trabajo ${ }^{26}$. Por lo tanto, el razonamiento realizado por el Tribunal Constitucional, fuerza concluir que solo será inconstitucional una privación absoluta del medio de impugnación.

Entonces, habiendo incluso elevado consulta una Corte por la eventual inconstitucionalidad del inciso tercero del artículo 501 del Código del Trabajo, corresponde analizar las garantías del debido proceso que se verían vulneradas por la interpretación actual de dicho precepto legal, como fundamento previo de una eventual nueva interpretación.

\section{EL DERECHO A UNA SENTENCIA FUNDADA ${ }^{27}$ Y EL DERECHO AL RECURSO ${ }^{28}$}

Los nuevos procesos orales se han caracterizado, tanto por la oralidad, como por un sistema de valoración libre de la prueba, limitado por la sana crítica. Cuando el sistema de valoración de la prueba es legal, el legislador le indica al juez cuáles son los medios probatorios y su valor. El sistema de valoración libre, como ocurre en la sana crítica, permite

25 En este sentido, véase: SAAVEDRA CON HipermerCado LA SERENA LIMITADA (2010); BARRIENTOS CON DAVILA (2010); URRUTIA CON LEIVA (2016).

26 Requerimiento de inaplicabilidad pos inconsitutucionalidad del Magistrado señor Rodrigo Biel Melgarejo presidente subrogante de la ilustrísima Corte de Apelaciones de TalCa respecto del inciso final del artículo 501 del Código del Trabajo, en la Causa Rit No M-37-2009 (2009). Sentencia, que además, observa que en el caso concreto el tribunal de instancia sí realizó un análisis somero de los elementos que no tenía obligación de consignar y, todavía más interesante, declara que: "la inaplicabilidad del precepto impugnado (que contiene una regla singular para el procedimiento monitorio) solo provocaría la aplicación de la norma supletoria ya indicada -artículo 459 del Código del Trabajo, ubicado en el párrafo $3^{\circ}$, sobre procedimiento de aplicación general-, la que, como se ha dicho, ha sido observada por el fallo". El Tribunal Constitucional observa que, en caso de no existir esta norma especial, se debiera aplicar el régimen general del art. 459 CT que sí obliga a fundar y motivar la sentencia del modo al que habitualmente estamos acostumbrados los operadores jurídicos.

27 Llama poderosamente la atención como De la Oliva y Peitado (2014) p. 275, en sus lecciones introductorias para estudiantes, afirman categóricamente y sin mayores cuestionamientos "Los autos y sentencias son resoluciones necesariamente motivadas" entregando una máxima tan absoluta que, pareciera, no poder violarse bajo ninguna condición.

28 Muy pertinente en la comprensión de este tema: Palomo y Alarcón (2011) pp. 291-320. 
que el juez utilice simple y llanamente su intelecto ${ }^{29}$, alcanzando esta afirmación a diversas expresiones como el leal saber y entender, las reglas de la sana crítica, las máximas de la experiencia, etcétera ${ }^{30}$. Mas el éxito $-o$ fracaso- de este sistema probatorio radica en buena parte en la posibilidad de control ${ }^{31}$ de la decisión jurisdiccional que pasa, necesariamente, por una motivación y una fundamentación adecuadas ${ }^{32}$.

La sana crítica es forma parte de un sistema de valoración en que las partes tendrán libertad para incorporar los medios de prueba que estimen oportunos; el juez gozará de autonomía individual para valorar la prueba, y su razonamiento solo estará limitado por los principios de la lógica, las máximas de la experiencia y los conocimientos científicos afianzados. Entregada tal holgura al sentenciador, toma más importancia la fundamentación y motivación que él haga de sus sentencias ${ }^{33}$. La RAE define fundamentar como establecer la razón o el fundamento de una cosa, y es precisamente lo que se le pide al juez, que señale cuáles fueron las razones y fundamentos de su decisión ${ }^{34}$. La exigencia de fundamentación de las sentencias judiciales, como bien enfatiza la doctrina ${ }^{35}$, es un mandato constitucional que deriva directamente de lo que ha de entenderse por un procedimiento racional y justo ${ }^{36}$.

29 Pero lejos de significar que el juez puede hacer lo que se le antoje cayendo en arbitrariedades, lo cierto es que la mejor doctrina matiza esta idea indicando que: "el valor probatorio de la prueba debe ser establecido por el juzgador caso por caso, de forma discrecional y sin estar vinculado por reglas abstractas y generales", pero "la valoración discrecional de la prueba debe realizarse en forma intersubjetiva y controlable". TARUFFO (2008) pp. 136-137.

30 Nieva (2011) p. 94.

31 TARUfFo (2005) p. 185: "la única forma de velar por el respeto de dichos límites es mediante la obligación que tiene el juez de motivar la sentencia, por medio de la cual deberá justificar mediante argumentaciones racionales sus propias elecciones, quedando estas por tanto sometidas al control externo".

32 Como excelentemente explica Romero Seguel (2017) p. 81-98, la fundamentación de las sentencias es una materia que ha sufrido una importante evolución histórica, en tanto se trata de un requisito que, en ocasiones, ha sido dispensado. Al margen de las garantías que en sí mismo protege el debido proceso, existen dos garantías procesales particulares que toda sentencia ha de cumplir: debe estar fundamentada y debe ser congruente con las peticiones. Concluye Romero (2017) p. 87 que la utilización incorrecta del sistema de ponderación de la prueba puede configurar el agravio consistente en falta de fundamentación de la sentencia.

33 En idéntico sentido Hunter (2015) pp. 158-159: "Por eso, con justa razón la doctrina opina que la motivación es uno de los pilares sobre los que descansa el ordenamiento procesal moderno. Constituye una garantía que posibilita la actuación de las demás garantías fundamentales, especialmente la de la imparcialidad y la estricta sujeción del juez a la ley; a la vez, permite descartar cualquier arbitrariedad e irracionalidad de la decisión judicial. Se dice que de nada serviría establecer un estatuto de garantías fundamentales si a los jueces no se les obliga a fundamentar sus decisiones, a explicar por qué razón deciden escoger la regla de Derecho aplicada, o porqué razón tal o cual medio de prueba reafirma la existencia de un hecho”.

34 En el caso español, la mejor doctrina ha subrayado que se trata de una obligación constitucional, derivada del principio de tutela judicial efectiva, que impone que las sentencias estén motivadas y que la motivación no solamente exista, sino que además sea suficiente. Montero (2014) p. 211.

35 Domínguez (2010) p. 159.

36 Bordalí (2014) p. 43, reconoce que si bien no hay ninguna norma constitucional que disponga expresamente que las resoluciones judiciales deben estar motivadas o fundadas, esto se infiere necesariamente del art. 19 No 3 inciso $6^{\circ}$ de la Constitución Política. Un proceso o un procedimiento (como expresión formal) no podrán ser racionales si la sentencia no está debidamente fundamentada. 
Fundamentar y motivar sus sentencias es un deber ineludible de los jueces ${ }^{37}$ que consiste en que los jueces den razones a los justiciables, y a la sociedad en su globalidad, sobre el porqué de su decisión ${ }^{38}$ y, permitir que este requisito sea soslayado por los sentenciadores socava al sistema judicial mismo desde que, produce la indefensión de las partes, pues estas no podrán impetrar sus recursos ante instancias superiores al no conocer los razonamientos del sentenciador ${ }^{39}$. Lo que nos lleva a otra de las garantías que se ve afectada por la actual interpretación del artículo 501: el derecho al recurso.

Un tema de gran sensibilidad para el usuario de la administración de justicia es, precisamente, el grado de control que un sistema procesal reconoce de las resoluciones que dictan los jueces ${ }^{40}$. Sin pretender demostrar profusamente nuestra premisa ${ }^{41}$, el derecho al recurso tiene su fundamento en los Tratados Internacionales que forman parte de nuestro ordenamiento jurídico en virtud del artículo $5^{\circ}$ inciso $2^{\circ}$ de nuestra Carta Fundamental, más específicamente en el artículo 8.2.h de la Convención Americana de Derechos Humanos y en el artículo 14.5 del Pacto Internacional de Derechos Civiles y Políticos ${ }^{42}$. Corresponde precisar que la misma Corte Interamericana, a través de su rol consultivo, ha establecido que lo señalado para los casos penales es plenamente aplicable para materias civiles, laborales o fiscales ${ }^{43}$, en este sentido las pautas de interpretación utilizadas por la $\mathrm{CIDH}$, como el principio pro homine, el principio de interpretación extensiva y el principio de interpretación progresiva tienden a evitar problemas de interpretación que restringen el alcance de los derechos o devalúan su garantía ${ }^{44}$.

Ahora bien, establecido el derecho al recurso como una garantía de las personas, para que este sea eficaz debe constituir un medio adecuado para la revisión de la sentencia errónea. Ello requiere que se pueda analizar cuestiones fácticas, probatorias y jurídicas ${ }^{45}$ en que se basa la sentencia impugnada. En la actividad jurisdiccional existe una interde-

37 Acudiendo a nuestros clásicos, AnABAlón (2015) p. 436: "De sobra comprensible resulta el verificar la importancia de la función que corresponde y desarrolla el juez frente a la prueba rendida en la causa y con miras a la dictación de la sentencia definitiva"; p. 437: "a los mismos jueces del fondo les corresponde en forma privativa resolver acerca del verdadero significado y alcance de los hechos que se desprenden de tales pruebas"; p. 439: "Respecto de esta función de tanta trascendencia en todos sus aspectos, no hay que olvidar uno de los deberes más elementales de los jueces del fondo dentro de la consideración de los hechos del pleito, cual es el de distinguir los que han sido aceptados o reconocidos por las partes y aquellos sobre los cuales, precisamente, haya versado la controversia o la propia controversia [...]”. Existe un deber de todo sentenciador de hacerse cargo de la narración de los hechos y la valoración de la prueba, más allá incluso del juicio ordinario. El propio ANABALÓN (2015) pp. 443 y 445 va a terminar explicando que incluso en los supuestos de apreciación de la prueba en conciencia se debe dar cuenta de la motivación y no debe significar eludir los antecedentes de los que, a la vista, dispone el enjuiciador.

38 Bordalí (2016) p. 119, quien subraya esta característica como un deber que el Estado de Derecho exige a sus jueces.

39 GonZÁlez (2006) p. 105.

40 NúNEZZ (2008) p. 199.

41 Puede consultarse para un conocimiento profundo de la posición que adscribimos, PALOMO y LorCA (2017) pp. 38-48.

42 También, puede verse en contra de esta posición FuENTES y RIEGO (2017) pp. 295-314.

43 Opinión Consultiva No 11 de la Corte Interamericana de Derechos Humanos (1990) p. 8.

44 Letelier (2014) p. 144.

45 Valenzuela (2013) p. 718. 
pendencia entre las determinaciones fácticas y la aplicación del derecho ${ }^{46}$, de forma tal que una errónea determinación de los hechos implica una errada o indebida aplicación del derecho. Consecuentemente, las causales de procedencia del recurso deben posibilitar un control amplio de los aspectos impugnados de la sentencia condenatoria ${ }^{47}$. Por lo tanto, la $\mathrm{CIDH}$ establece como requisito fundamental para que se configure el derecho al recurso, que puedan ser revisados por un tribunal superior tanto los hechos como el derecho objeto del juicio, situación que no se da en el recurso de nulidad laboral consagrado, actualmente, como único medio de impugnación de las sentencias laborales, ya que, como sabemos, es un recurso que exige causales determinadas que se circunscriben solo a la aplicación del Derecho. Entenderlo de esta forma es aceptar solo la visión del recurso como un control jerárquico y no como una garantía de las personas ${ }^{48}$.

En este orden de ideas, si consideramos que la nulidad laboral, único mecanismo de impugnación de las sentencias definitivas en materia laboral, ya representa una palmaria limitación del derecho al recurso de las partes ${ }^{49}$, que impide al tribunal superior revisar los hechos $^{50}$ y lo circunscribe solo a la revisión de la legalidad de la sentencia ${ }^{51}$, la interpretación actual del inciso tercero del artículo 501, que liberaría al sentenciador de la obligación de motivar sus resoluciones, hace imposible entrar a revisar si aquella ha sido pronunciada con infracción manifiesta de las normas sobre apreciación de la prueba conforme a las reglas de la sana crítica (artículo 478 letra b) ${ }^{52}$. Por lo tanto, la exégesis actual del mentado artículo representa una vulneración de la garantía fundamental del derecho al recurso. Para corregir dicha situación no es necesaria una modificación legal, sino solo una interpretación que permita armonizar el contenido literal del texto normativo con las garantías fundamentales recientemente descritas.

Nos centraremos en una relectura del artículo $501 \mathrm{CT}$, no obstante, se debe dejar de manifiesto que el artículo 502 CT al indicar qué recursos proceden en contra de la sentencia lo vincula al recurso de nulidad y, fácilmente se podría concluir que la sana crítica exige que el juez analice toda la prueba ${ }^{53}$.

\footnotetext{
46 GuASCH (1998) p. 183: "toda distinción entre hecho y derecho debe ser vista con mucha relatividad, pues los hechos que importan son los destinados a penetrar en el derecho. No se trata de que la distinción sea absoluta sino que para su posible diferenciación es necesario eliminar toda visión antitética”.

47 Caso Mohamed Versus ARgentina (2012).

48 Palomo (2010) p. 469.

49 Palomo y Lorca (2017) p. 62: "no podemos sino concluir que, en la práctica, en sede de nulidad laboral, no se respeta la garantía del derecho al recurso, en particular, su exigencia de revisión integral de lo decidido, lo que sin lugar a dudas representa una cuestión de la que la dogmática, pero principalmente la jurisprudencia, debe hacerse cargo y desplegar esfuerzos por remediarla".

50 En el orden procesal penal, lo señalaba con claridad Cortez (2006) p. 220: "La importancia de la motivación fáctica radica en que el control de los errores de derecho por parte del tribunal ad quem solo es posible de realizar sobre una base fáctica correctamente descrita. En ello radica precisamente la justificación de que se eleven a causales de nulidad los vicios de la motivación de la sentencia en cuanto a los hechos".

51 Si bien es cierto que existen algunas manifestaciones que, desde la dogmática más que la forense, defienden la posibilidad de revisar hechos mediante el recurso de nulidad laboral (AstudiLlo (2012) pp. 269-284).

52 Contreras con Makluf (2015).

53 Agradecemos esta observación a uno de los árbitros ciegos.
} 


\section{REINTERPRETACIÓN DEL INCISO TERCERO DEL ARTÍCULO 501 DEL CÓDIGO DEL TRABAJO}

Partiendo, entonces, de la premisa que la interpretación actual del inciso tercero del artículo 501 del Código del Trabajo es vulneradora de las garantías del debido proceso (derecho a una sentencia fundada y el derecho al recurso) se propone una revisión crítica de la misma, que nos permita armonizar el contenido de las sentencias de los procedimientos monitorios con los estándares mínimos del debido proceso ${ }^{54}$.

Con el objeto de superar este inconveniente procesal, planteamos la siguiente exégesis de la norma: el inciso tercero del artículo 501, al establecer los elementos que debe contener la sentencia, está regulando el "veredicto" ${ }^{55}$ que debe dictar el juez al final de la audiencia, en ningún caso al contenido de la sentencia definitiva, la que, como es deseable, deberá contener todos los elementos establecidos en el artículo 459 CT, que no son otros que los exigibles a toda sentencia definitiva. Esta interpretación, adicionalmente, se vería reforzada por la modificación que introdujo la Ley No 20.974 que, al observar el déficit que se producía, insertó un inciso $4^{\mathrm{o}}$ que permite posponer hasta por tres días la dictación de la sentencia ${ }^{56}$ $y$, en ese supuesto, nada justifica que se realice omitiendo los requisitos generales ${ }^{57}$. Hay que

54 En una lectura a propósito del proceso penal, pero que sin duda es trasladable a la teoría general del proceso, entre los derechos que, al menos, componen el contenido del racional y justo procedimiento MatURANA y López (2010) p. 31 identifican que la resolución del conflicto debe realizarse mediante una sentencia fundada.

55 Término que se usa comúnmente para referirse a la resolución dictada en forma oral que el juez entrega clausurado el debate y en que se pronuncia sobre el acogimiento (o no) de la petición y entrega someramente algún fundamento. Se comenzó su uso a propósito de la reforma procesal penal, si bien es cierto que la ley no habla propiamente del mismo. CAROCCA (2009) p. 165, entonces, al explicar cómo se alcanza el iter hasta la sentencia definitiva en el proceso penal señala que una vez se ha cerrado el debate y se ha obtenido un acuerdo en la deliberación judicial se comunicará la decisión sobre la absolución o condena: "pronunciamiento que se denomina habitualmente veredicto, por su equivalencia al que se emite por los jurados".

56 Motivo por el que llama la atención que en algunos casos complejos es encomiable como los jueces son capaces de dictar sentencia inmediata, después de un receso en el que tampoco sabemos con claridad -aunque sí lo sospechamos- el tribunal ha estado preparando la resolución: CORPORACIÓN MUTUAL DE SEGUROS CON OVIEDO (2018). Sin embargo, debe reiterarse que se trata de supuestos en que no resulte posible dictar sentencia de inmediato, atendido a que no parece prudente hacerse cargo de todas las menciones de una sentencia en un breve lapso. No parece, al contrario, prudente usar excusas de administración "doméstica" como pretexto para aquello: "Atendido los antecedentes que se han ventilado y teniendo presente que existen tres audiencias que se encuentran retrasadas para el inicio de esta sala, se va a aplicar lo dispuesto en el artículo 501 inciso final [...]". Morocco con NueVA ERA IMPO Y EXP LTDA (2018).

57 Buen ejemplo de ello lo constituiría AGUILAR CON CARDENAS (2017) que hizo uso de esta facultad en un caso, que en princpio pudiéramos calificar de simple. En efecto, el demandado no compareció, por lo que la magistrado pudo haber simplificado los trámites dando por confeso de los hechos al mismo, sin embargo, se determinaron hechos a probar, medios probatorios y, entonces, la jueza hizo uso de la facultad dispuesta en el inciso final del art. 501 postergando la dictación de la sentencia. El "producto" (la sentencia) que dictó es de la misma calidad y menciones que una dictada bajo el régimen general. En un caso más complejo, también se aplicó esta posibilidad y la sentencia dictada se hace cargo de los puntos contemplados para el régimen general: MILLAN CON SERVICIOS DE OBRAS MENORES EN GENERAL TOMÁS CASTRO COPA (2018). Sin embargo, preocupa lo señalado en GARCIA CON DÍZZ (2018). El juez hizo uso de la facultad de postergar la dictación de la sentencia y pese a que de su lectura podemos, también, afirmar que cumple con todos los requerimientos del artículo 459, señala: "Que de conformidad a lo dispuesto en el artículo 501 del Código del Trabajo en relación con el artículo 459 del mismo cuerpo legal, se omite en la sentencia la síntesis de la demanda, respecto de la cual se evacuó la contes- 
reconocer, en rigor, que nada se dice en esta regla que permita extraer esta propuesta en forma literal. Lo cierto es que la interpretación que proponemos parece apuntar en aquella dirección. Pero es justo destacar que no formó parte de la discusión de la Ley y que solamente es una inferencia que parece tener encaje en lo que venimos sosteniendo.

Para defender esta interpretación utilizaremos un argumento normativo, que nos demostrará que la figura del veredicto, entendiéndolo como la resolución que pronuncia el juez en audiencia, es un momento procesal previo a la sentencia definitiva, siendo esta última la que, eventualmente, puede ser objeto de recursos. Así, al ser hitos distintos, es de común entendimiento comprender que tienen requisitos distintos atendida su propia naturaleza, la que llevará, por ejemplo, a que las exigencias propias del veredicto sean menores a las que se deben observar en la sentencia definitiva.

Con el arribo de las reformas procesales nos encontramos con un juez que puede ser obligado a resolver en audiencia, a pocos minutos de la incorporación de los últimos medios de prueba e inmediatamente después de los alegatos finales. Frente a esa situación, es dable sostener que el legislador ha morigerado el contenido de la resolución que debe tomar el juez al final de la audiencia y, por otra parte, le ha entregado un plazo extra para resolver la contienda, el que normalmente será de algunos días. Dentro del primer caso, se encasillaría la relajación en la exigencia del contenido del veredicto dictado al final de la audiencia. El artículo 501 del Código del Trabajo autoriza al juez para obviar ciertos elementos del artículo 459 CT, aquellos de mayor dificultad de exposición y en los que podría tender a confusiones e, incluso, incurrir en eventuales nulidades.

Lo planteado anteriormente, en mayor o menor medida, se encuentra presente en todos los nuevos procesos orales vigentes en nuestro país. A continuación, desarrollaremos algunos ejemplos: En el sistema procesal penal y observando la sentencia definitiva del juicio oral, este cuerpo normativo hace una diferencia expresa entre el veredicto que se dictará al final de la audiencia correspondiente (artículo 343 CPP) y la sentencia definitiva (artículo $342 \mathrm{CPP}$ ). La sentencia definitiva deberá contener todos los elementos descritos en el artículo 342 CPP que, en esencia, son los que podríamos denominar clásicos. Sin embargo, el artículo 343 que establece los elementos que deberá contener el veredicto de absolución o condena (controversia sometida al conocimiento de los jueces) es menos extenso y solamente exige el pronunciamiento específico respecto a absolución o condena del acusado por cada uno de los delitos que se le hubiesen imputado y, específicamente se deben emitir los fundamentos principales tomados en consideración para llegar a las conclusiones. Aun con todo, parece más exigente que lo regulado en el ámbito laboral.

Es importante, empero, destacar que el sentenciador al referirse al veredicto y la sentencia definitiva tiende a confundirlos, sin embargo, los diferencia claramente.

La Ley No 19.968 regula las contiendas relativas al Derecho de Familia. Y, de la misma forma que el Código Procesal Penal, también diferencia claramente entre veredicto y sentencia definitiva. Así, el artículo 65 que señala: "una vez concluido el debate, el juez comunicará de inmediato su resolución, indicando los fundamentos principales tomados

tación en la audiencia de estilo, solicitando su rechazo, constando íntegramente en el registro de audio de dicha audiencia”. De modo que, pareciera que el juez considera que no deben cumplirse los requisitos del art. 459 y, solamente, debe representarse lo dispuesto en el art. 501 CT. 
en consideración para dictarla. Excepcionalmente, cuando la audiencia de juicio se hubiere prolongado por más de dos días, podrá postergar la decisión del caso hasta el día siguiente hábil, lo que se indicará a las partes al término". Por lo tanto, si consideramos que el artículo 65 establece el contenido del veredicto que debe dictar el juez al final de la audiencia respectiva, debemos concluir que los requisitos establecidos para este son menos rigurosos que los establecidos para la sentencia definitiva, ya que solo debe contener los fundamentos principales tomados en consideración para dictarla. Y, continuando con la misma lógica, encontraremos los requisitos de la sentencia definitiva en otro artículo y, de la misma forma que en el proceso penal, estos serán más precisos permitiendo alcanzar los beneficios señalados a lo largo de este estudio.

Es destacable, en este momento, mencionar que incluso el mismo Código del Trabajo, cuando regula el procedimiento de aplicación general, diferencia claramente entre el veredicto y la sentencia definitiva. Del primero dice que se podrá dictar al final de la audiencia o dentro del plazo de décimo quinto día hábil (artículo 457 CT) para luego, en un artículo diferente (artículo 459 CT) establecer el contenido de la sentencia definitiva. Por lo tanto, no establece requisitos mínimos para aquel veredicto que debe dictarse en audiencia, pero resguarda el debido proceso estableciendo claramente los elementos que debe contener la sentencia definitiva (artículo 459).

En conclusión, aceptar que el inciso tercero del artículo 501 establece los elementos que debe contener el veredicto que dicta el juez al final de la audiencia respectiva y que, en consecuencia, la sentencia definitiva deberá cumplir con todos los requisitos establecidos en el artículo 459, es una interpretación lógica, acorde a la realidad jurídica que presentan los nuevos procesos orales y, como se demostró, ya presente en varios de dichos procedimientos. Resulta más difícil de aceptar -a nuestro entender- una interpretación que vulnere principios tan básicos como el derecho de todo ciudadano a conocer los razonamientos que utilizó un juez para resolver una contienda que llevamos ante su imperio.

\section{LA HISTORIA FIDEDIGNA DE LA LEY}

Ahora bien, planteada una interpretación "garantista" del inciso tercero del artículo 501, corresponde hacerse cargo de uno de los obstáculos más significativos que podría enfrentar su aceptación. Considerando la importancia que tiene para la interpretación de una Ley su historia fidedigna, importancia incluso consagrada en el artículo 19 de nuestro Código Civil, corresponde investigar si en dicha historia se manifestó algún ánimo expreso que consagrara la exégesis clásica y descartara la que hemos planteado en los párrafos anteriores.

El artículo 501 del Código del Trabajo se incorporó a nuestro ordenamiento jurídico en el año 2008, con la Ley 20.087 que sustituye el procedimiento laboral contemplado en el libro V del Código del Trabajo. Su redacción original era la siguiente: "Esta audiencia será preparatoria y se desarrollará en conformidad con lo establecido en el artículo 453. La audiencia de juicio tendrá lugar dentro de los 20 días siguientes, y se desarrollará de acuerdo a lo establecido en el artículo 454"58. Por lo tanto, originalmente el artículo 501 tenía solo dos

\footnotetext{
58 LEY No 20.087, de 2006.
} 
incisos; el mentado inciso tercero llegaría con la modificación legal establecida en la Ley 20.260, que modificó el Libro IV del Código del Trabajo y la Ley 20.087.

Contrario a lo que se esperaría, en relación a un cambio tan significativo, la discusión respecto a su incorporación fue más bien sucinta. Mientras, por una parte, la iniciativa legal de la Ley No 20.260 desarrolla un fundamento para cada uno de los artículos que busca modificar, no ocurre así con el artículo 501 y debemos remitirnos al mensaje del proyecto para entender su lógica. El mensaje presidencial de la Ley 20.260 señala los siguientes objetivos ${ }^{59}: 1$. Profundizar los principios de celeridad y concentración, que resultan claves para la oportuna resolución del conflicto, la que viene exigida por la naturaleza de los derechos que se reclaman en sede laboral. 2. Reforzar el principio de inmediación que inspira todo el proceso, entregando al juez del trabajo las herramientas que le permitan conocer directamente y a cabalidad la controversia que debe resolver. 3. Evitar potenciales dificultades e incertidumbres que algunas de las normas aprobadas podrían producir en la tramitación de los procedimientos. 4. Introducir reformas a los procedimientos monitorio y de reclamación de multas, con el fin de simplificarlos y darles un carácter más breve y expedito. Como se desprende claramente de los objetivos planteados en el mensaje, la finalidad principal de la modificación legal es simplificar y entregar celeridad a la resolución de conflictos, especialmente al procedimiento monitorio.

En el Congreso, durante la tramitación en la Comisión de Constitución, Legislación y Justicia, el inciso tercero del artículo 501 despertaría la atención del abogado presidente de la Asociación de Abogados Laboralistas, Diego Corvera Vergara, siendo el único partícipe que se refirió al polémico artículo, señalando que la sentencia que recae en el procedimiento monitorio, como también sobre el de multas administrativas, no contempla una debida fundamentación por cuanto no analiza la probanza rendida ni los hechos que se estiman probados como tampoco el razonamiento que conduce a dicha estimación (artículo 459 No 4) lo que atentaría no solo contra el debido proceso, sino también contra la lógica procesal ${ }^{60}$. La modificación propuesta por el Ejecutivo se aprobó sin debate y por unanimidad.

La observación realizada fue, en definitiva, el único debate que despertó el artículo 501 en su tramitación legislativa, la que incluyó un control de constitucionalidad del mismísimo Tribunal Constitucional.

Por lo tanto, en toda la tramitación legislativa que derivó en la incorporación a nuestro ordenamiento jurídico del inciso tercero del artículo 501 del Código del Trabajo, no observamos mayores razonamientos o debates específicos que nos puedan entregar fehaciencia respecto a una interpretación determinada. Por el contrario, para entender su incorporación debemos recurrir a los objetivos generales del proyecto de ley que, como es lógico, tienen a la celeridad y simplificación como principales objetivos. No parece razonable, empero, que esta celeridad pueda exceder los estándares mínimos del debido proceso.

\footnotetext{
59 Historia de la Ley No 20.087 (2007) p. 4.

${ }^{60}$ Historia de la Ley 20.260 (2008) p. 27.
} 


\section{JURISPRUDENCIA MENOR: EL JUEZ DE LETRAS SALVA LOS PROBLEMAS}

Metodológicamente, este apartado lo confeccionamos con una muestra aleatoria. Tomamos la última causa ingresada en 2017 que obtuvo una sentencia monitoria tras celebrarse la audiencia única, en todos los tribunales especializados del país. Adicionalmente, se incluyeron en esta toma de datos alguna sentencia cercana en la fecha, pero de tribunal no especializado, o más antigua, con el objetivo de poder contrastar los datos obtenidos. El resultado llama la atención: pese a lo declarado por las Cortes de Apelaciones y por la letra expresa de la ley, los jueces laborales realizan una síntesis de los hechos, principales alegaciones de las partes y de gran parte -sino toda- la prueba ${ }^{61}$ ante ellos presentada, pese a reconocer que no tienen la obligación de hacerlo ${ }^{62}$. Entonces, podríamos estar tratando un problema que la práctica soluciona por sí misma, pero lo cierto es que no parece prudente ni razonable que quede al simple arbitrio de cada tribunal establecer aquellos requisitos más importantes para el enjuiciamiento y su eventual control. Aquello solamente puede ser fuente de desiguales aplicaciones de la ley y, a la postre, de injusticia.

Recurrentemente, los jueces especializados en la jurisdicción del trabajo, utilizan el primer considerando para narrar lo prescrito en el numeral $3^{\circ}$ del art. 459, es decir una síntesis de los hechos y principales alegaciones ${ }^{63}$. Adicionalmente, es unánime el uso de varios considerandos para resumir la prueba presentada ${ }^{64}$, indicar qué hechos se entienden por probados y el razonamiento por el que aquello sucedió ${ }^{65}$. Al punto de consignarse, también, los hechos no discutidos ${ }^{66}$ o llegar a indicar que se valoraron otros medios de prueba, y que no cambian el signo de la decisión ${ }^{67}$.

En esta línea, podemos encontrar agradables sorpresas que, con prolijidad y velando, entonces, por una mejor entrega de Justicia, dedican un considerando a exponer qué hechos se fijaron como pertinentes, controvertidos y siendo sustanciales fueron objeto de prueba para, posteriormente, exponer qué prueba rindió cada uno describiendo qué alcan-

\footnotetext{
${ }_{61}$ Incluso, existen supuestos que, en principio llaman a huir de determinadas fórmulas "Que la reclamante y la reclamada rindieron la prueba de que da cuenta el acta que precede a la presente sentencia. Posteriormente realizaron las partes las observaciones a la prueba rendida"; pero que, sorprendentemente, después se hacen cargo de qué pruebas fueron las más importantes y qué hechos, entonces deben darse por acreditados. GEOSTAR S.A. CON INSPECCIÓN PROVINCIAL DEL TRABAJO DE SAN FELIPE (2018).

${ }^{62}$ Arenas con Arancibia (2017): "Que, de conformidad con lo dispuesto en el artículo 501 inciso final del Código del Trabajo las sentencias dictadas en el procedimiento monitorio solo requieren de las menciones señaladas en el artículo 459 № 1, 2, 5, 6 y 7 del Código del ramo”.

63 Así, por ejemplo, LARA CON AGUILAR (2017).

64 Normalmente, separada por la presentada por el actor y por el demandado ARENAS CON ARANCIBIA (2017).

65 Por ejemplo, en LARA CON AGUILAR (2017) el juez indica en su considerando noveno analiza la prueba rendida: "Que sin embargo ese relato carece de antecedentes relevantes para estimara si existió una relación laboral entre las partes de este juicio (...)” para concluir en el siguiente considerando, después de desgranar lo obtenido por ese escaso medio probatorio: "Que, claramente la prueba ha sido insuficiente en este juicio para lograr un estándar de convicción, toda vez que el relato del primer testigo (...)”. El considerando noveno de ARENAS CON ARANCIBIA (2017) se titula "Análisis de los antecedentes".

66 ARENAS CON ARANCIBIA (2017).

67 ZAGAL CON BMC INTERNACIONAL (2018).
} 
ces introdujo cada parte, para, finalmente, indicar qué hechos quedaron demostrados a su juicio $^{68}$. Sin duda hay un compromiso con la calidad de la Justicia que, afortunadamente, se sobrepone a lo que el legislador consideró.

Incluso, llega a sorprender que jueces despachen quince considerandos y describan con un excelente nivel de detalle el porqué comprenden acreditados algunos hechos o descarten otros ${ }^{69}$.

Entonces, llegamos a la conclusión que los jueces no pronuncian sentencias "completas", "complejas", o "clásicas" si se prefiere, solamente en aquellos casos en que la demandada no contesta y no comparece el demandado y, por tanto, se aplica el apercibimiento contemplado en el art. 453 No 1, inciso 7, en virtud del cual, al estimarse tácitamente admitidos los hechos, en realidad carece de sentido algo más complejo que acoger las peticiones de plano ${ }^{70}$. Ahora bien, esta circunstancia, debe estar específicamente consignada en la sentencia, de lo contrario su incorporación es discutible ${ }^{71}$. E incluso, en algún caso, se rinde prueba con la rebeldía del demandado ${ }^{72}$.

Lo que sucede, entonces, es que las Cortes de Apelaciones no entran a valorar el recurso de nulidad ${ }^{73}$, por regla general, aduciendo que pese a que la sentencia se haya hecho

68 ORTIZ CON LOICA (2016).

69 Es llamativo constatar como en CONTRERAS CON CHILEPRESS (2017) la jueza, alcanza a hacerse cargo de la prueba no valorada por no haber sido incorporada, en un gesto que honra su profesionalismo a la hora de resolver absolutamente impregnada de los detalles del supuesto de hecho, tal y como se constata de su sentencia. En parecidos términos GUZMÁN CON URRA (2018): "Que para arribar a las conclusiones precedentes, la prueba incorporada por las partes ha sido apreciada con sujeción a las reglas de la sana critica, desestimándose en su fuerza probatoria los demás medios de prueba que también fueron individualizados en los considerandos segundo, tercero y cuarto anteriores, pero que no fueron mencionados expresamente en los siguientes considerandos y razonamientos de esta sentencia, toda vez que su mérito probatorio no logra alterar en nada lo que se viene decidiendo y se dirá en lo resolutivo".

70 Navarrete con Constructora armas LtDA (2017); Vera con Maza (2018); Guercelus con Mam (2018); CAIMILLA CON FIERRO SUR SPA (2018). Incluso ante este supuesto, algunos jueces exponen los hechos que se van a tener por admitios, en tanto no surgen de un probatorio contradictorio: RODRIGUEZ CON AHUMADA (2018); CASANUEVA CON DURÁN (2018); FERRERO CON ORTIZ (2018). De este modo, concordamos con lo resuelto en BECERRA CON ILICH (2018): "Que no habiendo hechos sustanciales, pertinentes y controvertidos sobre los cuales fijar la interlocutoria de prueba, se considerará que todo lo que ha leído este juez en el considerando primero y segundo son efectivos (...)". Como se expresa, en casi idéntico sentido, en CASTILlO CON NILO (2018): "Que conforme lo dispone el artículo 500 del Código del Trabajo, en estos juicios el Juez puede acoger la demanda de plano, con mayor razón puede hacerlo una vez que ha sido emplazado el demandado para defenderse, situación tal como queda reflejada en esta audiencia el demandado ha rechazado ejercer este derecho".

71 Circunstancia que no se da en CONSTANZO CON WEITZMAN (2018) cuestión que abre la puerta a pensar que la sentencia no cumple con el estándar mínimo deseable, puesto que se acoge la demanda sin que la demandada rebelde, especialmente, pueda conocer los fundamentos, ni que fuera declarada en tal calidad y, por lo tanto, se le aplicaron los apercibimientos que establece el Código del Trabajo.

72 Navarro con Alfa ChILE Zona Sur SPA (2018);

73 Pese a que la forma no es exactamente idéntica entre todas las Cortes de Apelaciones, lo cierto es que se repiten pronunciamientos similares a: "Tratándose la sentencia recurrida de una pronunciada en un procedimiento monitorio, resultan aplicables en cuanto al contenido de la sentencia que se pronuncie dicho procedimiento, las disposiciones del artículo 501 del Código del Trabajo. Luego, no es obligatorio para el sentenciador que la sentencia que dicte contenga "el análisis de toda prueba rendida, los hechos que estime probados y el razonamiento que conduce a esta estimación”, por cuanto por expreso mandato legal, artículo 501 del Código del Trabajo, está eximido de precisar aquello en la sentencia” (ARAVENA CON SERVICIOS GASTRONÓMICOS Sushi KING Limitada (2017). 
cargo de las menciones excluidas, no debió hacerlo y, por lo tanto, no es revisable en sede de recurso de nulidad ${ }^{74}$. Cuestión que, claramente, no deja de representar una paradoja.

Excepcionalmente, se pueden encontrar situaciones bien anómalas en que un juez omite dictar sentencia y, solamente, consigna un extracto que acompaña al acta única de audiencia. Esta práctica, que esperamos no se extienda por los tribunales, responde a una lectura amplia de lo que prescribe el art. 62 del acta 71 de la Excma. Corte Suprema. En efecto, la citada disposición habla de las sentencias dictadas en audiencia -las que podrán solamente contar con una transcripción de la parte dispositiva del fallo- que no debiese aplicarse a las sentencias emanadas de procedimientos monitorios, en tanto aquellas, deben dictarse al término de la audiencia, es decir acabada y cerrada la misma ${ }^{75}$.

\section{CONCLUSIONES: VEREDICTO, SENTENCIA Y RESOLUCIÓN FUNDADA}

La actual interpretación del inciso tercero del artículo 501 del Código del Trabajo libera al juez de la obligación de motivar debidamente sus sentencias en el procedimiento monitorio laboral, al entender que el legislador no establece, entre los elementos que debe contener dicha sentencia, una síntesis de los hechos y de las alegaciones de las partes, el análisis de toda la prueba rendida, los hechos que estime probados y el razonamiento que conduce a esta estimación. Esta interpretación, ampliamente aceptada por nuestras Cortes de Apelaciones, no solo representa una vulneración al derecho a una sentencia debidamente fundada, sino que mutila a un punto inaceptable el derecho al recurso (ya disminuido por la naturaleza propia del recurso de nulidad laboral). Es justo destacar que tanto el derecho a una sentencia debidamente fundada como el derecho al recurso son estándares mínimos del debido proceso, y que la obligación de motivar debidamente una sentencia se vuelve aún más importante cuando el sistema de valoración de la prueba es el de la sana crítica.

Afortunadamente, los tribunales instancia, en términos generales, realizan una labor más allá de lo que el tenor literal de la ley pareciera establecer, resguardando, entonces, aquellas garantías del debido proceso y, reflejamente, cargando aquella responsabilidad a las Cortes de Apelaciones.

Una correcta interpretación del inciso tercero del artículo 501 del Código del Trabajo, sin embargo, nos entrega la siguiente conclusión: dicho inciso solo establece los elementos que debe contener el veredicto que el juez puede o debe dictar al final de la audiencia, que, en consecuencia, son menos rigurosos que los señalados para la sentencia definitiva. Por lo tanto, la sentencia de un procedimiento monitorio laboral debe cumplir

74 Por aquello, llama poderosamente la atención algunos fallos como OYARZO CON READY MIX CENTRO (2017): "Que, a mayor abundamiento, pese a encontrarnos en un procedimiento monitorio, en donde no se exige un mayor análisis de la prueba rendida, analizados los fundamentos respectivos de la sentencia recurrida, se aprecia una adecuada y completa ponderación de la prueba rendida, sin evidenciarse en dicha ponderación una infracción que encuentre coincidencia con las causales denunciadas por el recurrente".

75 Consúltese, ZúñIga con SALMONES Aysen (2017); CANO CON SALAS (2018); ARAVENA CON SociedAd DE INGENIERIA ELÉCTRICA EL ALERCE SPA (2018). Llama la atención por lo escueto y por la constatación de pobreza jurisdiccional que esta lectura genera: VELIS CON VIVIENDAS 2000 LTDA (2018). Sin embargo, es una posibilidad que parece menos descabellada cuando se aplica la admisión tácita por rebeldía de la demandada: COATAL CON EMPRESA CONSTRUCTORA SigRo (2018). 
con todos los requisitos señalados en el artículo 459 del Código del Trabajo, incluidos los razonamientos relativos a la prueba, y el inciso tercero del artículo 501 solo se refiere a los elementos que debe contener el veredicto que el juez dicta al final de la audiencia respectiva. Esta interpretación es armónica con las garantías del debido proceso y responde a la naturaleza propia de los nuevos procesos orales, razón por la cual, es fácilmente reconocible en el resto de los procedimientos en que el juez puede o debe señalar su veredicto al final de una audiencia.

La interpretación propuesta en ningún caso atenta contra el objetivo de celeridad propio de estos procedimientos, máxime si consideramos el recientemente incorporado inciso cuarto del mismo artículo, que autoriza al juez, siempre que se trate de causas de interés colectivo o causas que presenten mayor complejidad, a dictar la sentencia respectiva hasta en un plazo de tres días de terminada la audiencia, por lo tanto, esta resolución no sería un veredicto dictado en audiencia y tendría que cumplir con todos los requisitos del artículo 459 del Código del Trabajo, razón por la cual el legislador no incluyó la morigeración de requisitos del veredicto en este nuevo inciso y solo lo mantuvo en aquel pronunciamiento que "debe hacer el juez en audiencia", esto es, en el inciso tercero. Con la incorporación del nuevo inciso cuarto, la sentencia del juicio monitorio quedó en una situación muy similar a la establecida en la Ley No 19.968, norma en la que podemos observar claramente la diferencia entre veredicto y sentencia definitiva.

\section{BIBLIOGRAFÍA CITADA}

Anabalón, Carlos (2015): Tratado de Derecho procesal civil. El juicio ordinario de mayor cuantía (Santiago, El Jurista Ediciones Jurídicas).

Astudillo, Omar (2012): El recurso de nulidad laboral. Algunas consideraciones técnicas (Santiago, Thomson Reuters).

Bordalí, Andrés (2014): "Primera Parte. Cuestiones Preliminares" en Bordalí, Andrés; Cortez, Gonzalo y Palomo, Diego (eds.), Proceso Civil. El juicio ordinario de mayor cuantía, procedimiento sumario y tutela cautelar (Santiago, Thomson Reuters) pp. 3-115.

Bordalí, Andrés (2016): Derecho Jurisdiccional (Valdivia, Derecho Austral).

Calamandrei, Piero, (2006): El procedimiento monitorio (Buenos Aires, Librería El Foro).

Correa, Juan Pablo (1998): El proceso monitorio (Barcelona, Editorial José María Bosch).

Couture, Eduardo (1951): Fundamentos de derecho procesal civil (Buenos Aires, Depalma).

Delgado, Jordi (2015): "El procedimiento monitorio civil en la Reforma Procesal Civil: ¿Puro o documental?", Revista Chilena de Derecho y Ciencia Política, Vol. 6, No 3: pp. 11-35.

Delgado, Jordi (2015): Estudios a propósito de la llegada del monitorio civil a Chile (Santiago, Ediciones Jurídicas de Santiago).

DomíngueZ, Álvaro (2010): "Orientaciones jurisprudenciales sobre la motivación de las sentencias en el procedimiento monitorio", Revista Chilena de Derecho del Trabajo y la Seguridad Social, Vol. 1, No 1: pp. 153-159.

Fuentes, Claudio y Riego, Cristian: "El debate sobre los recursos en materia civil y la jurisprudencia de la Corte Interamericana de Derechos Humanos", en Palomo, Diego; 
Delgado, Jordi y Núñez, Raúl (Eds.), Recursos Procesales. Problemas Actuales (Santiago, DER Ediciones) pp. 295-314.

GonZÁlEZ, Joel (2006): "La fundamentación de las sentencias y la sana crítica", Revista Chilena de Derecho, Vol. 33, No 1: pp. 93-107.

GuAsch, Sergi (1998): El Hecho y el Derecho en la casación civil (Barcelona, Bosch).

Hernández, Patricio (2012): Procedimiento monitorio laboral: Estudio crítico a la luz del debido proceso y del derecho comparado (Santiago, Editorial Librotecnia).

Horvitz, María Inés (2003): Derecho Procesal Penal Chileno (Santiago, Editorial Jurídica de Chile).

Humeres, Héctor (2010): "Los recursos de nulidad y unificación: un apunte foral", Revista Chilena del Trabajo y de la Seguridad Social, Vol. 1, No 2: pp. 187-197.

Hunter, Iván (2015): La aplicación judicial del Derecho en el proceso civil. Doctrina, jurisprudencia y derecho comparado (Santiago, Thomson Reuters).

LanaTA, Gabriela (2011): Manual de proceso laboral (Santiago, Thomson Reuters).

LANATA, Gabriela (2011): El sistema de recursos en el proceso laboral chileno (Santiago, LegalPublishing Chile).

Letelier, Enrique (2014): "El derecho fundamental al recurso según la doctrina jurisprudencial del sistema interamericano de protección de los derechos humanos", Revista Europea de Derechos Fundamentales, Vol. 23, No 1: pp. 141-160.

Maturana, Javier (2014): Sana Crítica. Un sistema de valoración racional de la prueba (Santiago, Thomson Reuters).

Maturana, Cristián y Montero, Raúl (2010): Derecho Procesal Penal. Tomo I (Santiago, Abeledo Perrot LegalPublishing).

Montero, Juan (2011): La prueba en el Proceso Civil (Madrid, Thomson Reuters).

Montero, Juan (2013): Derecho Jurisdiccional II. Proceso Civil (Valencia, Tirant lo Blanch)

Montero, Juan (2014): Derecho Jurisdiccional I. Parte General (Valencia, Tirant lo Blanch).

Navarro, René (2011): El juicio monitorio en el Derecho procesal laboral chileno. Dogmática y Praxis (Santiago, Ediciones Jurídicas de Santiago).

Nieva, Jordi (2011): "Los sistemas de valoración de la prueba y la carga de la prueba: nociones que precisan revisión”, Revista de Derecho Procesal, Vol. 4, No 3: pp. 91-120.

Nieva, Jordi (2014): Derecho procesal I. Introducción (Madrid, Marcial Pons).

NúNEEZ, Raúl (2008): "El sistema de recursos procesales en el ámbito civil en un Estado democrático deliberativo", Revista Ius et Praxis, Vol. 1, No 14: pp. 199-223.

Orellana, Fernando (2008): Comentarios al Nuevo Proceso Laboral (Santiago, Librotecnia).

Orellana, Fernando (2010): "Cuestiones procesales del procedimiento monitorio regulado en el Código del Trabajo y la forma de proceder en los casos de aplicarse las normas sobre régimen de subcontratación", Revista Chilena de Derecho del Trabajo y de la Seguridad Social, Vol. 1, No 2: pp. 61-70.

Orellana, Fernando (2015): "El procedimiento monitorio civil contemplado en los proyectos de Código Procesal Civil y su comparación con el proceso monitorio laboral regulado en el Código del Trabajo, en Delgado, Jordi (ed.), Estudios a propósito de la llegada del monitorio civil a Chile (Santiago, Ediciones Jurídicas de Santiago) pp. 139-156. 
Palavecino, Claudio y Ramírez, Cristián (2010): "Examen crítico de la sentencia anticipada en el procedimiento monitorio laboral", Revista Chilena de Derecho del Trabajo y la Seguridad Social, Vol.1, No 2: pp. 75-97.

Palomo, Diego (2010): "Apelación, doble instancia y proceso civil oral. A propósito de la reforma en trámite", Revista Estudios Constitucionales, Vol. 8, № 2: pp. 465-524.

Palomo, Diego (2011): "Fundamentación de la sentencia y contradicción, como materialización del derecho al recurso en materia procesal penal”, Revista Ius et Praxis, Año 17, No 1: pp. 291-320.

Palomo, Diego (2015): Proceso y Justicia laboral: Lecturas a contracorriente (Santiago, Ediciones Jurídicas de Santiago).

Palomo, Diego y Lorca, Nelson (2017): "Sistema recursivo en los modelos reformados de la Justicia chilena: ¿Un avance o un retroceso?”, en Palomo, Diego; Delgado, Jordi y Núñez, Raúl (Eds.), Recursos Procesales. Problemas Actuales (Santiago, DER Ediciones) pp. 25-87.

Pereira, Rafael (2010): El procedimiento monitorio laboral (Santiago, Legal Publishing).

Pérez, Álvaro (2006): "En torno al procedimiento monitorio desde el derecho procesal comparado europeo: caracterización, elementos esenciales y accidentales", Revista de Derecho de la Universidad Austral de Chile, Vol. XIX, No 1: pp. 205-235.

Romero, Alejandro (2017): Curso de Derecho Procesal Civil, Tomo IV. De los Actos procesales y sus efectos (Santiago, Thomson Reuters).

TARUfFo, Michele (1975): La motivazzione della sentenza civile (Padova, Cedam).

TARUfFo, Michele (2005): El vértice ambiguo: Ensayos sobre casación civil (Lima, Palestra).

TARUfFo, Michele (2008): La prueba (Madrid, Marcial Pons).

VALDÉs, Diego (2014): "Procedimiento "monitorio" Laboral Chileno: entre la celeridad y la garantía", Revista Estudios Jurídicos Democracia y Justicia, No 3: pp. 100-123.

Valenzuela, Williams (2013): "Reflexiones sobre el derecho al recurso a partir de la sentencia "Mohamed vs. Argentina" de la Corte Interamericana de Derechos Humanos: Cuestiones a tener en consideración sobre el sistema recursivo en el Proyecto de Código Procesal Civil”, Revista de Estudios Constitucionales, Vol. 11, No 2: pp. 713-736.

\section{JURISPRUDENCIA CITADA}

Caso Mohamed versus Argentina (2012): Corte Interamericana de Derechos Humanos. Sentencia del 23 de noviembre de 2012. Serie C No 255.

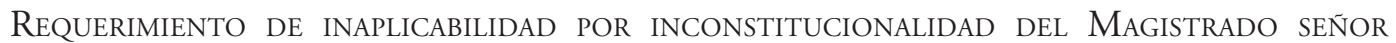
Rodrigo Biel Melgarejo presidente subrogante de la ilustrísima Corte de Apelaciones de Talca respecto del inciso final del artículo 501 del Código del Trabajo, EN LA CAUSA RIT No M-37-2009, SEGUIDA POR INTERPOSICIÓN DE RECURSO DE NULIDAD EN la causa caratulada Valdés con Bravo (2009): Tribunal Constitucional chileno, Rol No 1514, 12 de octubre de 2009.

SaAvedra con Hipermercado La Serena Limitada (2010): Corte de Apelaciones de La Serena, 26 de noviembre de 2010 (recurso de nulidad laboral) en www.pjud.cl. Fecha de consulta 30 de noviembre de 2017. 
BARrientos con DÁVILA (2010): Corte de Apelaciones de Talca, 10 de diciembre de 2010 (recurso de nulidad laboral) en www.pjud.cl. Fecha de Consulta 30 de noviembre de 2017.

Contreras con MakLuF (2015): Corte de Apelaciones de Valparaíso, 16 de abril de 2015 (recurso de nulidad laboral) en www.pjud.cl. Fecha de consulta 30 de noviembre de 2017.

OyARZO CON READY MIX CENTRO S.A. (2017): Corte de Apelaciones de Puerto Montt, 25 de enero de 2017 (recurso de nulidad), en www.pjud.cl. Fecha de consulta 30 de noviembre de 2017.

Gonzalez Rodríguez con Pomerape S.A (2016): Corte de Apelaciones de Arica, 10 de agosto de 2016 (recurso de nulidad laboral), en www.pjud.cl. Fecha de consulta 30 de noviembre de 2017.

URRUtia CON LeIVA (2016): Corte de Apelaciones de San Miguel, 2 de noviembre de 2016 (recurso de nulidad laboral), en www.pjud.cl. Fecha de consulta 30 de noviembre de 2017.

Hernández con Ilustre Municipalidad de Panguipulli (2017): Corte de Apelaciones de Valdivia, 9 de marzo de 2017 (recurso de nulidad laboral) en www.pjud.cl. Fecha de consulta 30 de noviembre de 2017.

Randstad Con Inspección del trabajo de Coyhaique (2017): Corte de Apelaciones de Coyhaique, 14 de marzo de 2017 (recurso de nulidad laboral), en www.pjud.cl. Fecha de consulta 30 de noviembre de 2017.

Servicios Limitada con Inspección Provincial del trabajo de Santiago (2017): Corte de Apelaciones de Santiago, 6 de abril de 2017 (recurso de nulidad laboral), en www.pjud.cl. Fecha de consulta 30 de noviembre de 2017.

Aravena con servicios gastronómicos Sushi King LtDa (2017): Corte de Apelaciones de Iquique, 5 de mayo de 2017 (recurso de nulidad laboral), en www.pjud.cl. Fecha de consulta 30 de noviembre de 2017.

ZÚNIGA CON SALMONES AYSEN (2017): Juzgado de Letras del Trabajo de Castro, 22 de septiembre de 2017 (acción por despido injustificado), en www.pjud.cl. Fecha de consulta 30 de noviembre de 2017.

NAVARRETE CON OYARZUN (2017): Juzgado de Letras del Trabajo de Copiapó, 27 de ocubre de 2017 (acción de nulidad de despido), en www.pjud.cl. Fecha de consulta 30 de noviembre de 2017.

Aguilar CON OJEDA (2017): Juzgado de Letras del Trabajo de Punta Arenas, 29 de noviembre de 2017 (acción por despido injustificado), en www.pjud.cl. Fecha de consulta 30 de diciembre de 2017.

Rodríguez con Ahumada (2018): Juzgado de Letras del Trabajo de San Bernardo, 2 de enero de 2018 (acción de nulidad de despido), en www.pjud.cl. Fecha de consulta 1 de marzo de 2018.

Cano con SALAS (2018): Juzgado de Letras del Trabajo de Puerto Montt, 2 de enero de 2018 (acción de nulidad de despido y cobro de prestaciones), en www.pjud.cl. Fecha de consulta 1 de marzo de 2018.

Cotal con Empresa Constructora Sigro (2018): Juzgado de Letras del Trabajo de Valparaíso, 4 de enero de 2018 (acción de nulidad de despido), en www.pjud.cl. Fecha de consulta 1 de marzo de 2018. 
FERRERO CON ORTIZ (2018): Juzgado de Letras del Trabajo de Chillán, 5 de enero de 2018 (demanda por nulidad de despido y cobro de prestaciones), en www.pjud.cl. Fecha de consulta 1 de marzo de 2018.

OVALle con servicios de obras menores en General sociedad Tomas CAstro Copa (2018): Juzgado de Letras del Trabajo de Antofagasta, 8 de enero de 2018 (acción de nulidad de despido y cobro de prestaciones), en www.pjud.cl. Fecha de consulta 1 de marzo de 2018.

GEOSTAR S.A. CON INSPECCIÓN PROVINCIAL DEL TRABAJO DE SAN FELIPE (2018): Juzgado de Letras del Trabajo de San Felipe, 8 de enero de 2018 (impugnación de multa), en www.pjud.cl. Fecha de consulta 1 de marzo de 2018.

Casanueva con DuRÁn (2018): Juzgado de Letras del Trabajo de Puente Alto, 8 de enero de 2018 (acción de nulidad de despido), en www.pjud.cl. Fecha de consulta 1 de marzo de 2018.

MOROCCO CON NUEVA ERA IMPO Y EXP LTDA (2018): Juzgado de Letras del Trabajo de Iquique, 9 de enero de 2018 (acción de nulidad de despido), en www.pjud.cl. Fecha de consulta 1 de marzo de 2018.

NAVARRo con Alfa Chile zona sur spa (2018): Juzgado de Letras del Trabajo de Valdivia, 9 de enero de 2018 (acción de nulidad de despido y cobro de prestaciones), en www.pjud.cl. Fecha de consulta: 1 de marzo de 2018.

CASTILlo CON SOCIEDAD DE TRANSPORTE SRT CIELO MINERA LTDA (2018): Juzgado de Letras del Trabajo de Arica, 10 de enero de 2018 (acción de nulidad de despido), en www.pjud.cl. Fecha de consulta 1 de marzo de 2018.

Corporación Mutual de SEguros con OVIEDo (2018): Juzgado de Letras del Trabajo de Concepción 10 de enero de 2018 (acción por desafuero maternal), en www.pjud.cl. Fecha de consulta 1 de marzo de 2018.

GUERCELUS CON MAM INVERSIONES LTDA (2018): Juzgado de Letras del Trabajo de San Miguel, 11 de enero de 2018 (acción por despido indebido), en www.pjud.cl. Fecha de consulta 1 de marzo de 2018.

Constanzo Con Weitzman (2018): Primer Juzgado de Letras del Trabajo de Santiago, 12 de enero de 2018 (acción por cobro de prestaciones), en www.pjud.cl. Fecha de consulta 1 de marzo de 2018.

VERA CON MAZA (2018): Juzgado de Letras del Trabajo de Coyhaique, 12 de enero de 2018 (acción por despido indirecto, nulidad de despido y cobro de prestaciones), en www.pjud.cl. Fecha de consulta 1 de marzo de 2018.

GUZMÁN CON URRA (2018): Segundo Juzgado de Letras del Trabajo de Santiago, 15 de enero de 2018 (acción por cobro de prestaciones), en www.pjud.cl. Fecha de consulta 15 de enero de 2018.

BECERRA CON ARAYA (2018): Juzgado de Letras del Trabajo de Rancagua, 15 de enero de 2018 (acción de nulidad de despido), en www.pjud.cl. Fecha de consulta 1 de marzo de 2018.

VELIZ CON VIVIENDAS 200 LTDA (2018): Juzgado de Letras del Trabajo de La Serena, 15 de enero de 2018 (acción por despido indebido), en www.pjud.cl. Fecha de consulta 1 de marzo de 2018. 
ARavena con SANDoval (2018): Juzgado de Letras del Trabajo de Temuco, 15 de enero 2018 (acción por despido injustificado), en www.pjud.cl. Fecha de consulta de 1 de marzo de 2018.

CAIMILla CON FIERRO SUR SPA (2018): Juzgado de Letras del Trabajo de Osorno, 15 de enero de 2018 (acción por despido improcedente y cobro de prestaciones), en www.pjud.cl. Fecha de consulta 1 de marzo de 2018.

ZaGAL CON BMC INTERNACIONAL ChILE (2018): Juzgado de Letras del Trabajo de Talca, 16 de enero de 2018 (acción de nulidad de despido, impugnación de despido y cobro de prestaciones), en www.pjud.cl. Fecha de consulta 1 de marzo de 2018.

GARCÍA CON Díaz (2018): Juzgado de Letras del Trabajo de Curicó, 19 de enero de 2018 (reconocimiento de relación laboral), en www.pjud.cl. Fecha de consulta 1 de marzo de 2018 